\title{
Aniquilando fronteras: hacia nuevos órdenes humanos. Desplazamiento y estrategias de reemplazo en Orgánico y Realia (Bucarest-Beirut)
}

\author{
Beatrice Lapadat
}

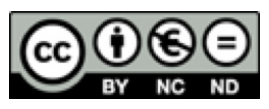

Esta obra está bajo una licencia Creative Commons Reconocimiento-No comercial-Sin Obra Derivada 
Artículos

\title{
Aniquilando fronteras: hacia nuevos órdenes humanos. Desplazamiento y estrategias de reemplazo en Orgánico y Realia (Bucarest-Beirut)*
}

\author{
Beatrice Lapadat \\ Universidad Laval, Canadá \\ beatrice.lapadat.1@ulaval.ca
}

Recibido: 28 de setiembre 2017 Aprobado: 28 de octubre 2017

Resumen

A lo largo de este ensayo se analiza la problemática de los encuentros interculturales, en el contexto performativo/teatral, tal y como los generan el desplazamiento, la transgresión de fronteras y los conflictos armados. El ensayo examina las estrategias de reemplazo por medio de los intercambios culturales y las mutaciones de identidad empleadas en el espectáculo teatral Orgánico, dirigido por Andrei Majeri (Teatro Nacional de Bucarest, 2014), y en la performance Realia (Bucarest-Beirut), de 2012, dirigido por Farid Fairuz. La hipótesis que impulsó esta investigación postula que el desplazamiento puede establecer nuevos terrenos para la interacción humana, por un lado, y para expresiones escénicas innovadoras por el otro. Si Orgánico destaca, con trasfondos más bien oscuros, tanto la deshumanización que implica el tráfico de órganos y la posibilidad de redención, Realia (Bucarest-Beirut) utiliza la autoficción, las identidades múltiples y el humor con el fin de denunciar firmemente la futilidad de las fronteras. Lo que fomenta un vínculo artístico e intercultural tan fecundo entre Orgánico y Realia son la transgresión de límites -tanto físicos como ideológicos- y la empatía que se siente hacia el Otro, que está bajo amenaza. A partir de estos mecanismos escénicos se analiza el impacto que un conflicto social pueda tener sobre las interacciones humanas. El concepto de desplazamiento empleado a lo largo de esta investigación está discutido dentro del marco conceptual establecido por la biopolítica de Foucault y por la teoría de la desterritorialización de Deleuze y Guattari.

Palabras clave: performance artístico; teatro; migración; desplazamiento; alteridad

* Originalmente este trabajo fue escrito en francés, la traducción al español fue realizada por Dorina Ivan, a quien agradezco profundamente. 


\begin{abstract}
It is within the scope of my essay to explore what I call the strategies of replacement by means of intercultural exchanges and identity mutations employed in the 2013 performance show Realia (Bucharest/ Beirut) by Farid Fairuz and the 2014 theatre show Organic, directed by Andrei Majeri (text by Saviana Stanescu). I argue that displacement - understood as an aesthetical and social concept at the same time- can finally establish a new ground for both human interaction and innovative stage expressions. Where Organic underlines both the dehumanization implied by organ trafficking and the possibility of redemption in rather dark tones, despite the abundant playful allusions, Realia uses autofiction, multiple identities and humour in order to denounce the futility of borders and cultural stereotypes. The transgression of boundaries, whether physical or ideological, is what constitutes the main liaison between the two stage performances. My aim is to use these dramaturgical mechanisms as points of departure for an analysis concerning the impact that a social conflict can exert upon human interactions. The concept of displacement is to be discussed mainly within the philosophical frame settled by Deleuze and Guattari, while Foucault's concept of biopolitics is most useful in order to emphasize the relation between the individual and his rapport with society and power in the context of immigration.
\end{abstract}

Key words: artistic performance; theater; migration; displacement; otherness 


\section{Estrategias de reemplazo en Realia (Bucarest-Beirut): la autoficción como performance}

En el invierno de 2010, un número considerable de bailarines, intérpretes, críticos y periodistas rumanos, inmersos en el entorno de las artes escénicas, recibieron, a través de Facebook, solicitudes de amistad y un mensaje virulento por parte de una persona llamada Farid Fairuz, cuya ocupación parecía involucrar la danza y la brujería. Lo más impactante fue que el presunto "artista libanés" acusaba a Mihai Mihalcea, uno de los bailarines y coreógrafos rumanos más reconocidos, por la forma excesivamente exigente y dictatorial como dirigía el Centro Nacional de Danza de Bucarest. Su página de Facebook también incluía una serie de detalles sobre su biografía: nacido en el Líbano, había sido criado por una pareja de pastores beduinos, hasta ser adoptado por "una familia rica de Jordania", porque sus padres -un judío y una libanesa -que siempre tuvieron que mudarse de un lugar a otro para proteger su relación prohibida - habían muerto durante la Guerra Civil de Beirut. Iniciado en la práctica mágica por los beduinos, Farid siguió una carrera en la danza profesional, en Europa y EEUU, entrelazando infatigablemente la danza y la brujería en sus actividades como intérprete.

Algunos meses después, los destinatarios del curioso mensaje por fin tuvieron la oportunidad de ver al artista en un performance concebido dentro de la misma institución cuyo director había acusado previamente. Al llegar el momento del estreno, "el secreto" ya había sido revelado. En efecto, Farid Fairuz resultó ser el alter-ego de Mihai Mihalcea quien, después de varios años como director del Centro Nacional de Danza, sintió que le urgía reinventarse como artista: "Yo necesitaba percibirme a mí mismo desde una posición exterior y revisitar una serie de cuestiones importantes y delicadas que no suelen discutirse en la sociedad rumana" (Visniec, 2015).

El proyecto, titulado Farewell! (or about the discrete oversights of the limbic system), fue recibido con una oleada de entusiasmo; la crítica en particular vio su empeño como un nuevo punto de partida para el entorno performativo rumano. Lo mismo podría decirse de Realia (Bucarest-Beirut), el espectáculo que creó en 2013 bajo la misma identidad y que discutiré en el presente ensayo. Al leer las reseñas y críticas sobre Realia, tanto en rumano como en inglés o francés ${ }^{1}$, es evidente que los analistas suelen destacar la intrincada red autobiográfica diseñada por el autor como instrumento performativo y la multiplicación posmoderna de las voces autorales en las cuales se basa la dramaturgia del performance.

Pero la intención del autor no fue necesariamente crear nuevos recursos performativos que le facilitaran la suscitación de una "revolución" artística, sino encontrar una manera más eficaz de abordar ciertas cuestiones socio-culturales, y especialmente -como él mismo acertó

\footnotetext{
${ }^{1}$ Varias críticas en francés e inglés están disponibles en http://faridfairuz.ro/project/realia/.
} 
en la citación del párrafo anterior -esas cuestiones que no logran ser suficientemente debatidas en su país de origen.

El tema de los refugiados de guerra y de cómo se convierten en los Otros a ojos de las sociedades en donde buscan refugio es fundamental en Realia (Bucarest-Beirut), aunque nunca está expresada como tal a lo largo del performance. Mucho antes de que la oleada de migrantes sirios captara la atención de los medios internacionales, a principios de 2015, Farid Fairuz había mostrado un interés sistemático en las sociedades del Oriente Medio tal y como se configuran ellas hoy: devastadas por conflictos, arrasadas por guerras, pero también teniendo en cuenta su potencial para el enriquecimiento y la redefinición del paradigma de la performance. Por otra parte, uno se puede preguntar cuál es la fina línea, si alguna existe, entre sacar a la luz al amenazado Otro o caer en las trampas de la apropiación cultural ilegítima.

En el siguiente análisis del desplazamiento, la desterritorialización y de lo que yo llamo las estrategias de reemplazo, se estudian en detalle los recursos que Farid Fairuz utiliza para reconciliar sus opiniones políticas y las estrategias performativas que desarrolla, con el fin de brindar una voz a una presencia que, si bien solía carecer de ella, siempre ha estado allí: el refugiado de guerra. El objetivo también es mostrar que, dentro de los confines de un contexto cultural rumano muy específico, las estrategias que él utiliza con el fin de hacer visible al Otro -es decir, esas estrategias que podrían ser percibidas como apropiación cultural-son, en efecto, tanto eficientes en términos de su impacto potencial, como también culturalmente conscientes.

En Mil mesetas, Deleuze y Guattari operan una distinción importante entre el concepto de migrante y el de nómada, tomando como término de referencia el proceso de desterritorialización (no obstante, es importante tener en cuenta que la manera en que ellos usan los términos antes mencionados es puramente conceptual y bajo ninguna circunstancia se podría aplicar a un análisis estrictamente socio-antropológico). El migrante solamente abandona un lugar para llegar a otro, sometiéndose voluntariamente a una reterritorialización, mientras el nómada controla por sí mismo las modulaciones de la desterritorialización, un proceso que llega a definirlo más allá de cualquier otra categorización:

The life of the nomad is the intermezzo. Even the elements of his dwelling are conceived in terms of the trajectory that is forever mobilizing them. The nomad is not at all the same as the migrant; for the migrant goes principally from one point to another, even if the second point is uncertain, unforeseen or not well localized... nomads have no points, paths, or land, even though they do by all appearances. If the nomad can be called the Deterritorialized par excellence, it is precisely because there is no reterritorialization afterward as with the migrant, or upon something else as with the sedentary ... With the nomad, on the contrary, it is deterritorialization 
that constitutes the relation to the earth, to such a degree that the nomad reterritorializes on deterritorialization itself [La vida del nómada es intermezzo. Incluso los elementos de su hábitat están concebidos en función del trayecto que constantemente los moviliza El nómada no debe confundirse con el migrante, pues el migrante va fundamentalmente de un punto a otro, incluso si ese otro punto es dudoso, imprevisto o mal localizado ... el nómada no tiene puntos, trayectos ni tierra, aunque evidentemente los tenga. Si el nómada puede ser denominado el desterritorializado por excelencia es precisamente porque la reterritorialización no se hace después, como en el migrante, ni en otra cosa, como en el sedentario. ... Para el nómada, por el contrario, la desterritorialización constituye su relación con la tierra, por eso se reterritoriliza en la propia desterritorialización] (Deleuze y Guattari, 2005, pp. 380-381).

Por lo tanto, es importante enfocar el hecho de que, para estos teóricos, la desterritorialización también conlleva otros significados diferentes de los que implica el simple proceso de desplazamiento. La desterritorialización se refiere, igualmente, a la manera en que el individuo elige adoptar o no la línea de vuelo (Deleuze y Guattari, 2005, p. 15) como una coordenada deliberada de sus acciones, o a la manera en que el individuo elige rechazar o no la reterritorialización que le ofrecen bajo los términos impuestos por el aparato estatal. Por eso, la desterritorialización, tal y como la entienden Deleuze y Guattari, no puede ser integralmente superpuesta a la noción del desplazamiento, a pesar de su aparente equivalencia.

Además, mantenemos la idea de que en la actualidad el arte del performance está potencialmente impregnado de la capacidad de dirigir tanto a los intérpretes como a los espectadores hacía diferentes manifestaciones de la desterritorialización, entendida como un concepto político y cultural radical que rechaza cualquier tipo de subordinación a la ideología del estado. Al mismo tiempo, los que participan en el proceso también toman más conciencia de la situación vulnerable, concreta, en la que el Otro ahí representado se encuentra con su vida real, fuera de los confines establecidos por las convenciones escénicas (indiferentemente que tan poco convencionales puedan ser las propuestas de la "escena").

Para volver a Realia (Bucarest-Beirut), la hipótesis es que, al hacer un performance autoficcional, Farid Fairuz actúa como un nómada deleuziano y adopta en el escenario estrategias de la desterritorialización, con el fin de ayudar a crear estrategias del reemplazo destinadas a tener una influencia eficiente fuera del escenario. De hecho, es innegable que, para este propósito, el intérprete no se abstiene de usar toda una constelación de clichés que indudablemente se relacionan con la audiencia original para la cual ha sido concebido el espectáculo - una audiencia predominantemente rumana-.

La exposición de estos estereotipos está ejecutada de tal manera que resultan relevantes tanto para los espectadores que vivieron -más o menos- bajo las condiciones impuestas por 
el régimen comunista (1944-1989), como para la audiencia más joven. Los últimos están, sin duda alguna, menos contaminados de los clichés difundidos por las voces segregacionistas o fundamentalistas y, en cambio, son conscientes de los clichés étnicos y religiosos que suponen una amenaza presente para nuestro mundo globalizado. Es por eso que la síntesis que el artista creó, entre los estereotipos predominantes en los años 1970, los de la niñez del narrador, y los estereotipos de hoy en día es tanto relevante como eficaz, por más desconcertante que esta superposición ficticia podría parecer durante una fase inicial de su recepción.

Para hablar en términos más concretos, me voy a enfocar en algunos ejemplos especí-

Figura 1. Farid Fairuz en Realia

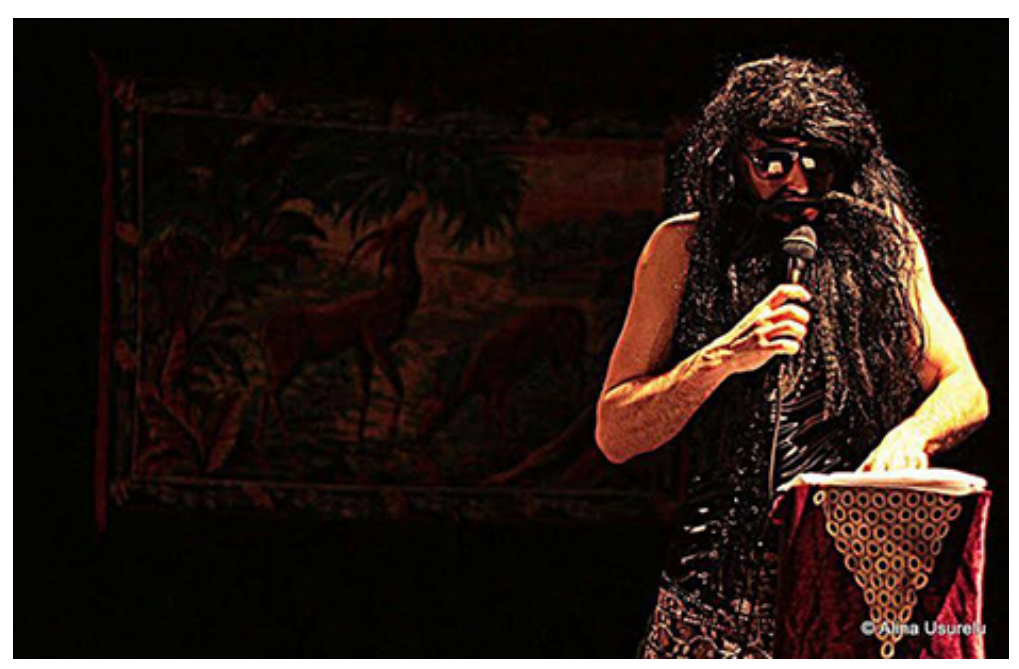

Fuente: Alina Usurelu

ficos. A pesar de que Farid se presenta como un huérfano libanés impactado por los horrores de la guerra en Beirut, su apelación implícita al público a favor de la aceptación y apertura hacia el Otro no está basada en hechos históricos reales del conflicto. En cambio, está fundada en referencias señalando abiertamente hacía el entorno social rumano de los años 1970. Con la excepción de un corto extracto de una película documental que el intérprete parece odiar ("Paren esa porquería") debido a la obvia actitud anti-libanés de uno de los hablantes, los límites de la aceptación social y cultural están siempre dirigidos hacia los prejuicios cultivados sistemáticamente entre los rumanos a lo largo de varios siglos. Su entera biografía inventada es un ejercicio que obliga a que la imaginación del espectador cree nuevos vínculos y acepte los retos propuestos por sus analogías.

El intérprete nació en el Líbano, pero el distrito donde vivió, Avenida Giurgiului, es en realidad uno de los más pobres de Bucarest. Más aún, mientras narra varias experiencias de su infancia, Farid recuerda cómo, cerca de la tienda de abarrotes donde la gente hacía fila para comprar naranjas, siempre había alguien diciendo que "estos libaneses las han inyectado". El más agudo miedo del niño -el de ser "raptado por los musulmanes" si les abre la puerta a desconocidos o si cruza la vía férrea-corresponde enteramente a uno de los mitos más populares dentro de la comunidad rumana, con la única diferencia de que musulmanes han de ser 
reemplazado por gitanos, indudablemente la más rechazada y desestimada de las minorías que viven en Rumania.

Al hacer esto, Farid Fairuz no sólo entreteje una atmósfera familiar para espectadores provenientes de distintos medios y generaciones, sino que asume él mismo los límites de su capacidad de representar al Otro, el desconocido que se encuentra en una situación peligrosa. En un determinado momento de la performance exhibe su cuerpo en movimiento envuelto en una atmósfera obviamente estereotipada. Lleva puesta una larga y reluciente capa, un imponente turbante, un corpiño negro, una mini-falda de látex, las mismas botas doradas y está cantando algo sobre "un niño hechizado". Tal secuencia puede resultar tanto graciosa como inquietante para los miembros de la audiencia, cuya niñez haya sido más o menos marcada por este tipo de marcas visuales específicamente orientales, ya sea a través de historias, fotografías, videos musicales o películas. Dicha secuencia resulta graciosa, ya que es reminiscente de un cierto periodo de la historia contemporánea rumana que precedió el contexto globalizado actual. Asimismo, resulta inquietante, porque posee cuestiones sobre si este nivel de la nostalgia puede ser transcendido para enfrentarse al lado oscuro de la historia del intérprete, una historia que hoy en día está adelantada y difundida por los refugiados de guerra.

Por lo tanto, Farid Fairuz crea una performance en la que entrega conscientemente el Otro a la audiencia, pero, al elegir una estrategia de representación ficticia, intercultural y lúdica, declara implícitamente que una representación auténtica de este personaje libanés como individuo afectado por un trasfondo político turbulento es inasequible. Aun así, dicha imposibilidad no lo impide a expresar fuertemente su declaración: ya es tiempo de que nos relacionáramos con el Otro que está bajo amenaza, ya es tiempo de aceptarlo a él y a su cultura, mientras desmantelamos nuestros clichés, incluso aunque tal proceso surge, al principio, desde un iluso "lugar de afección y curiosidad" (Haydon, 2013, párr. 9). De igual importancia es que su extravagante y a veces intencionadamente naif puesta en escena del "tipo libanés" también habla sobre los peligros de un enfoque puramente abstracto hacia el Otro.

El esquema podría ser sintetizado de este modo: la audiencia mira la perfomance del auto-titulado Farid Fairuz, el artista nacido en Beirut que buscó refugio en Europa y cuyas principales ocupaciones consisten, presentemente, en bailar y "entrar en los cuerpos de otras personas". No obstante, al mismo tiempo, la audiencia es perfectamente consciente de que la real identidad del artista que está sobre el escenario. Mihai/Farid utiliza su identidad libanesa como pretexto para exponer a los espectadores a los clichés culturales tan perdurables dentro de su sociedad con respecto a los grupos minoritarios, sean ellos los gitanos, los musulmanes, los miembros de la comunidad LGBTQ o personas pertenecientes a otra religión que la mayoritaria, que es el culto ortodoxo. 
Aún más, tanto los rumanos como los libaneses han tenido un contacto bastante influyente con el Imperio Otomano, el gran poder político y militar cuya presencia dentro del texto y de la evolución dramatúrgica está permanentemente aludida. Tanto los rumanos como los libaneses han tenido que hacer frente al trauma de un evento que los expulsó del dicho "mundo civilizado": "después de la caída del Imperio Otomano, el Líbano solía ser llamado la Suecia del Este... Pequeño Paris... "Exactamente lo mismo", donde "exactamente lo mismo" sirve de analogía con Bucarest, también llamado "El Pequeño Paris" durante el período de entreguerras.

En este contexto, Farid Fairuz parece tratar de comprobar si estas conexiones entre dos identidades étnicas distintas van a ser percibidas como tal por una audiencia que él espe-

Figura 2. Farid Fairuz en Realia

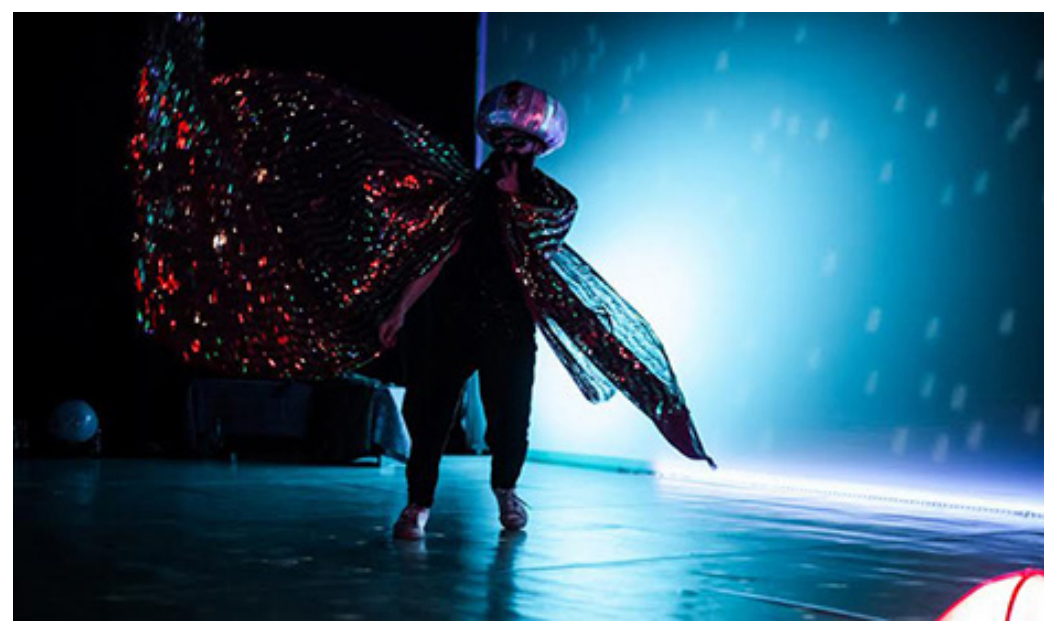

Fuente: Alina Usurelu ra que se muestre comprensiva y que sea capaz de recibir a un artista con "poderes sobrenaturales", que está huyendo de los horrores de la guerra. Por tanto, va señalando una serie de graves problemas procedentes del actual contexto internacional, con respeto a los inmigrantes y a las personas dispersadas por el mundo debido a las imposiciones de los conflictos militaros.

La elección de interpretar a un personaje cuya biografía inventada es susceptible de causar controversia es asumida y amplificada por la opción del intérprete de representarla a través del método de la autoficción, una fórmula narrativa que, de manera voluntaria y sistemática, desdibuja la línea entre las convenciones diegéticas y las identidades reales encontradas en el proceso de la representación (Stephenson, 2013, p. 24).

Aún más, las técnicas autobiográficas que mezclan el humor, la ironía y la concienciación social nunca se amparan en la complejidad "intrínseca" del enfoque posmoderno. Al contrario, el intérprete, como ya he indicado antes, simplemente opta por la técnica que le permite dirigirse de manera más eficiente a la comunidad a la que apunta. Dentro de este contexto, también es sumamente relevante mencionar que la dramaturgia es modificada de una performance a otra. El espectáculo es, por lo tanto, en sí mismo, una construcción "rizomórfica", en los términos de Deleuze y Guattari (2005, p. 15), en el sentido de que no existe una construcción 
finita y estable de la performance. Realia (Bucarest/Beirut) ha sido representado en Bucarest,

Figura 3. Farid Fairuz en Realia

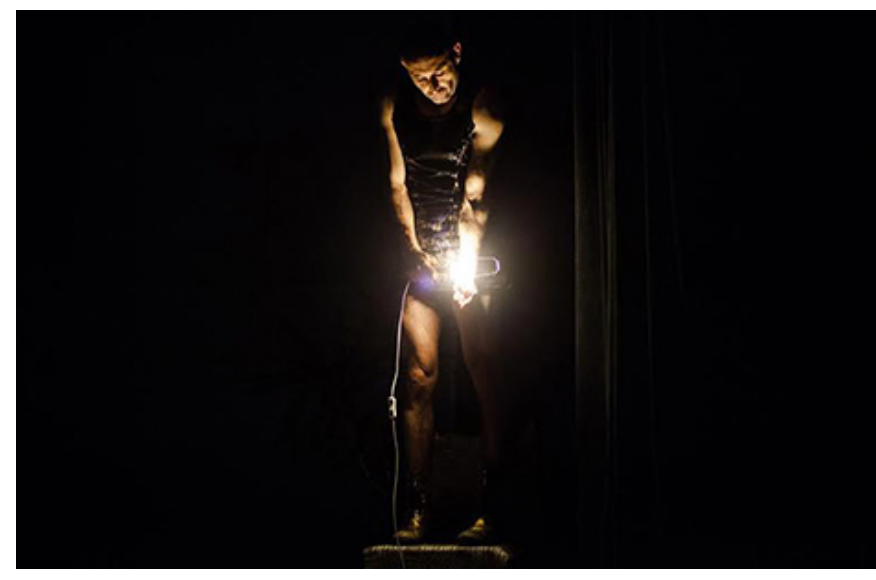

Fuente: Alina Usurelu
Bagnolet, Praga, Chemnitz, Sofía y ninguna representación se parece a las otras. Mientras mantiene los mismos componentes con respeto al tema de la identidad y las cuestiones sobre la naturaleza del performance, esta estructura fluida -que es característica de su obra- revela también la conciencia cultural del intérprete y su capacidad de adaptar sus herramientas performativas. Lo que en Bucarest funciona como una señal que toma en cuenta la historia común de los rumanos con los musulmanes y los gitanos puede funcionar, por su parte, en el contexto más occidental, lo hace un sutil signo de la imagen de los ciudadanos de Europa oriental.

Sin embargo, la suplantación realizada por Farid Fairuz no se desentiende de cuestiones éticas muy concretas, en particular con respecto a quienes están verdaderamente expuestos peligros en la vida real. En este sentido, hay una escena sumamente relevante en una de las versiones de la performance (Praga, 2014) que merece una discusión detallada en el contexto de la guerra y las comunidades dispersadas. El ritmo lúdico del performance es interrumpido cuando, de repente, el intérprete cambia de humor y deja de lado "todas las cosas resplandecientes" que llenan el centro de la escena. Entonces, se dirige a un rincón oscurecido. Allí, se posiciona en frente de una bombilla intensamente luminosa, mientras que la banda sonora vuelve al ruido de sirenas y bombas que se podía oír a principios de la performance.

A continuación, el intérprete empieza a mover la bombilla frente a sus brazos, simulando la automutilación. Mediante esta inserción, Farid Fairuz suspende temporalmente todas las convenciones previas, para hacer que la audiencia se percate de que, mientras los miembros y participantes de esa comunidad artística gozan del privilegio de la ficción, la estética y la búsqueda por el Otro a través de medios artísticos, el cuerpo de alguien muy parecido al desconocido representado en el escenario puede ser torturado por la guerra o debilitado por el hambre en el mismo momento del proceso performativo.

Sin embargo, una vez más, el intérprete invierte las expectativas de los espectadores, ya que nunca asume la posición de la víctima desamparada que espera ser rescatada por sus prójimos "civilizados" y empoderados. "Vine aquí para lanzar el hechizo de 
Figura 4. Silva Helena Schmidt et Lucian Teodor Rus en Orgánico

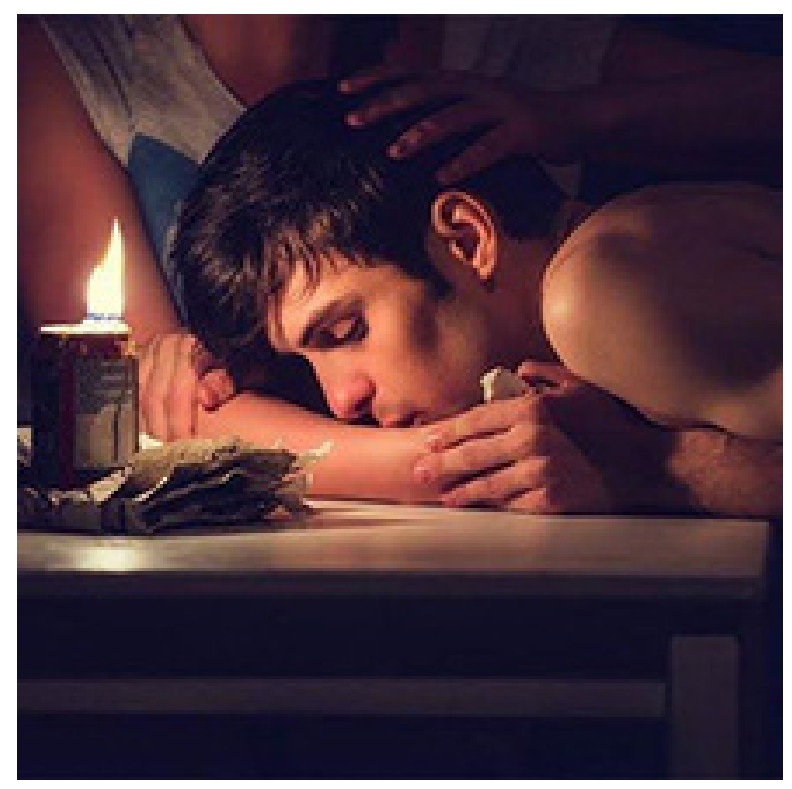

Fuente: Bogdan Botofei

la cultura rumana y para hacerlos deshacerse de sus traumas. Yo soy Farid Fairuz...", declara el intérprete de manera triunfante al final del performance. El refugiado que ofrece albergue y curación a los civilizados: ¿Podría ser este el futuro de Europa y América? ¿Podremos algún día - un día no tan lejano- reimaginar la performance a través de este lente?

\section{Orgánico: El Otro, entre Distorsión y} Adopción

En una conferencia impartida en Collège de France en 1979, Foucault hablaba, en el contexto de las políticas neoliberales en expansión durante los años 1970, sobre la relación de los migrantes con el poder económico. Declaraba que el migrante se compromete a una alta inversión y se expone a una serie de riesgos financieros con el fin de "obtener un mejoramiento de su estatus, de su remuneración ... La migración es una inversión; el migrante es un inversor" (2008, p. 230).

En Orgánico, la segunda performance teatral que se pretende analizar dentro del marco del desplazamiento, hacia el final del espectáculo se desarrolla una escena memorable. Un adolescente que, a lo largo de todo la performance, nunca había usado el lenguaje articulado para expresarse, por fin habla con claridad, dominando con confianza el espacio performativo: "América no es nada de lo que tú me contaste cuando tenía siete años, cuando tuve mi primera convulsión; estoy empezando a entender, mamá. Han matado a todos los cerdos y ahora algunos de nosotros, los que realmente amábamos a los cerdos, tenemos que reemplazarlos. Es como si fueran 'granjas humanas', mamá" (Stanescu, p. 30)2.

En el análisis de Orgánico se explora una vez más las estrategias del reemplazo empleadas por los personajes con el fin de afirmar su identidad. Además, mi objetivo es colocar a los personajes dentro del marco referencial foucaultiano de la biopolítica (2003), ya que todas sus

${ }^{2}$ Se precisa que las citas del texto de Saviana Stanescu corresponden al manuscrito inédito que data de 2014, con el cual Andrei Majeri recrea la puesta en escena de la pieza Orgánico. 
acciones parecen ser generadas, perturbadas e interrumpidas por la intervención del poder. Al utilizar el sentido que Foucault le da a la biopolítica, definida como "una nueva tecnología del poder" (2003, p. 242) que emplea tanto disciplina como "el poder de la regularización" (2003, p. 247), se intenta subrayar la trayectoria de la gradual deshumanización y re-humanización de los personajes. La intención consiste en trazar esta evolución y respectiva regresión, tanto en el contexto de la configuración social a la que están sometidos como en el contexto de su telaraña de interacciones.

Figura 5. Lucian Teodor Rus en Orgánico

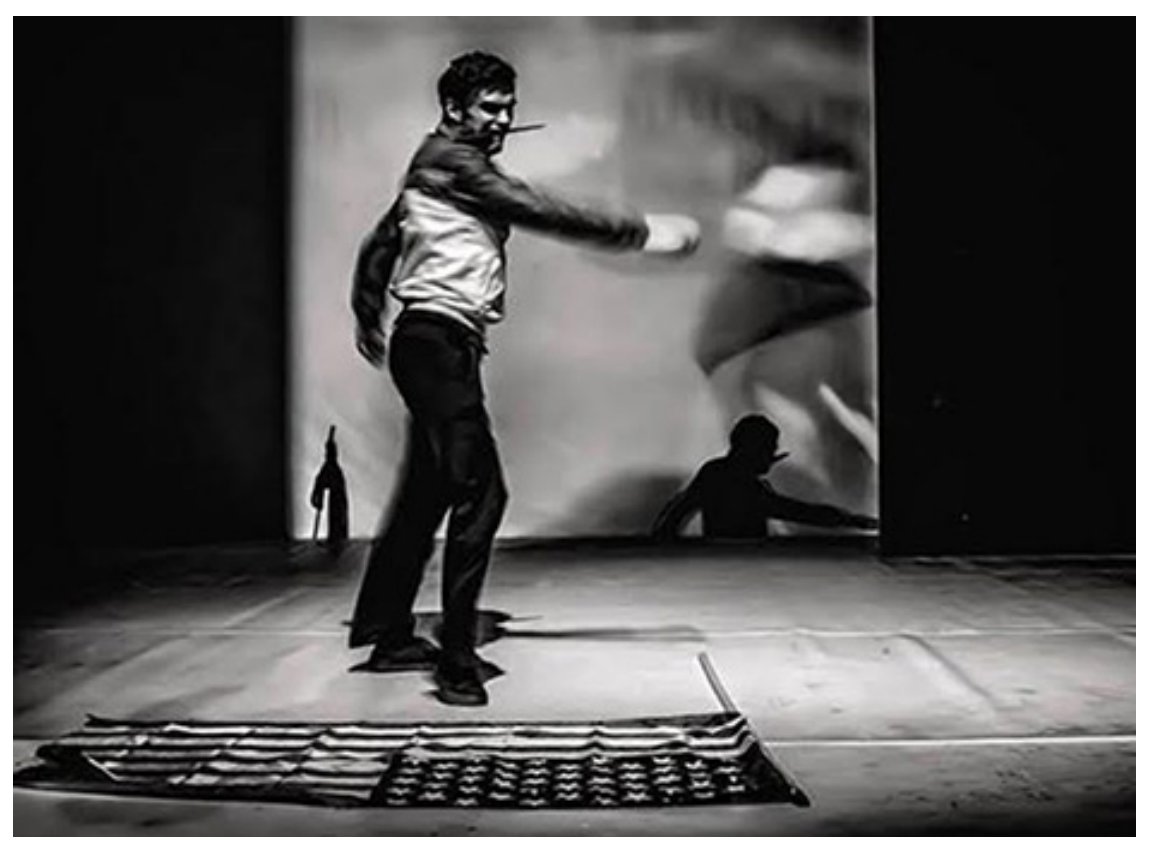

Fuente: Lucian Olteanu
El adolescente antes mencionado es Omy, un epiléptico de 20 años que llegó a New Jersey para que le extirparan un riñón a cambio de dinero. Kora y Chris, dos inmigrantes que "hablan el inglés con acento", cuidan de él mientras se realizan los trámites para su operación. Los tres personajes de Useless $^{3}$, una obra de Saviana Stanescu , están vinculados a través del mismo fracaso: el fracaso del sueño americano por el cual lo habían dejado y arriesgado todo. Bajo la dirección de Andrei Majeri, Useless fue estrenado en Bucarest como una pro-

ducción escénica en 2014 bajo un nuevo título, Orgánico. La obra, en las palabras de la autora, "es un drama de humor negro sobre el amor, los sueños y el tráfico de personas" (Teatro IRT, párr. 1) cuyos tres personajes son inmigrantes que se encuentran en situaciones vulnerables. No obstante, la diferencia fundamental entre Omy y la pareja que lo cuida temporalmente es que él desconoce por completo su estatus y la real razón de su presencia en los Estados Unidos.

\footnotetext{
${ }^{3}$ El estreno de la obra se dio en El Teatro IRT de Nueva York en agosto de 2014 y fue dirigido por José Zayas.
} 
Convulsiones, disfunciones lingüísticas, constante escapismo hacía un universo infantil y una clara incapacidad para las interacciones sociales y en las palabras de Chris: "Este chico está inútil, este chico" (Stanescu, p. 7). El espectador no tiene más que algunas alusiones sobre el pasado de Omy, ¿pero será que el chico tiene futuro? Una vez atrapado en la red del tráfico de personas, sin su consentimiento -que de todos modos tampoco sería capaz de dar- sus perspectivas para el futuro parecen tan oscuras como su presente. Pero allí está Kora: mientras que los traficantes sólo se muestran interesados en su riñón, Kora parece querer su corazón, como confiesa Omy en un soliloquio (Stanescu, p. 30). De hecho, ella está dispuesta a hacer lo que sea, aunque eso fuese bailar o vender su cuerpo, para salvar al chico: "Puedo hacer plata como en viejos tiempos. Ese "oficio" no se olvida, la gente dice que es como andar en bicicleta...

Imagen 6. Silva Helena Schmidt et Andrei Stehan en Orgánico

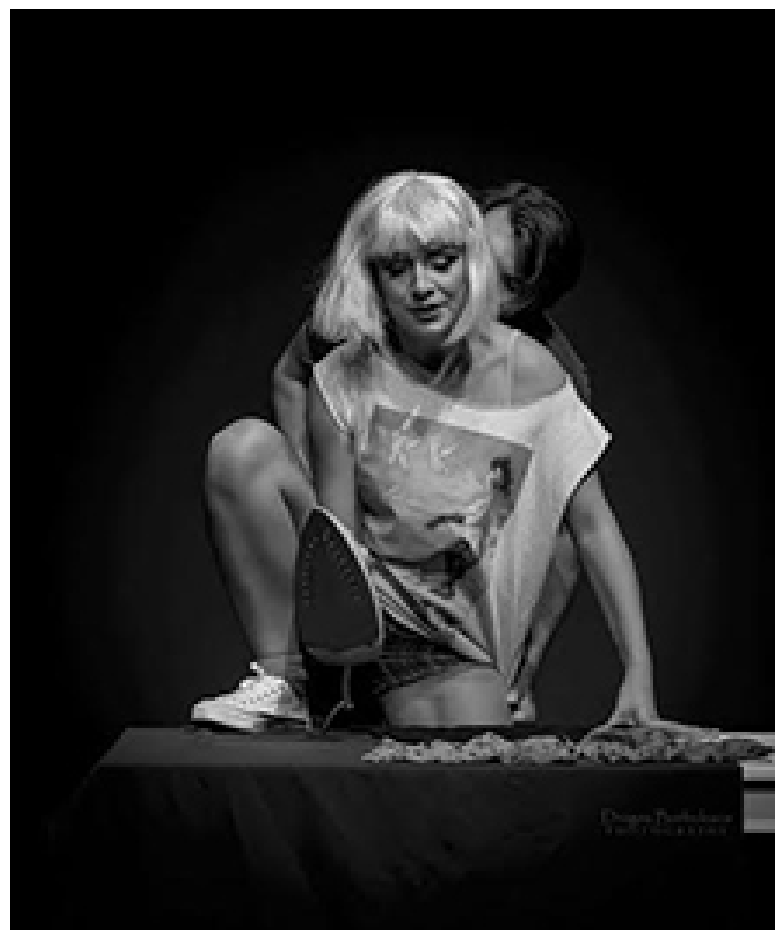

Fuente: Dragos Barbulescu
Puedo andar de nuevo en esa bicicleta. Sí que puedo. Es para una buena causa. Para ti, Omy. Y para mí" (Stanescu, p. 29).

Por tanto, el cuerpo de Kora es indicativo de lo que Foucault llamaba "la masificante confiscación del poder" (Foucault, 2003, p. 242), específica a las políticas neoliberales, que ven al individuo como a un instrumento que necesita ser regularizado a través del control de los nacimientos, los fallecimientos, la reproducción y la higiene. Fértil, pero no reproductiva, apta para el empleo pero desempleada, Kora es, en la escala social, tan "inútil" como el epiléptico Omy. La vigilancia que la biopolítica ejerce sobre el individuo ya no lleva al castigo, como lo hacía en la época que precede al neoliberalismo, y esto sólo puede empeorar la situación de los ciudadanos desarraigados como Omy y Kora, que son simplemente ignorados por el poder: "La soberanía tomó el vive y deja vivir; el poder de la regularización, en cambio, consiste en hacer vivir y dejar morir [énfasis agregado]" (Foucault, 2003, p. 247).

Antes de continuar con el análisis del espectáculo, he de mencionar que la manera cómo el joven director Andrei Majeri concibió la puesta en escena de la obra en el Teatro Nacional de Bucarest, la cual muestra un gran interés no solamente por la evolución de los personajes como 
comerciantes y donantes de órganos, respectivamente, sino también por su evolución paralela, "nocturnal", como individuos que adquieren angustias, esperanzas y fantasías en una atmósfera casi surrealista. Es solamente en el contexto de esta exploración simultánea de los eventos y los mundos interiores de los personajes que pueden ser entendidas por completo las interacciones humanas de la obra, sin caer en la trampa de las divisiones binarias tal y como "personajes

Imagen 7. Silva Helena Schmidt et Lucian Teodor Rus en Orgánico

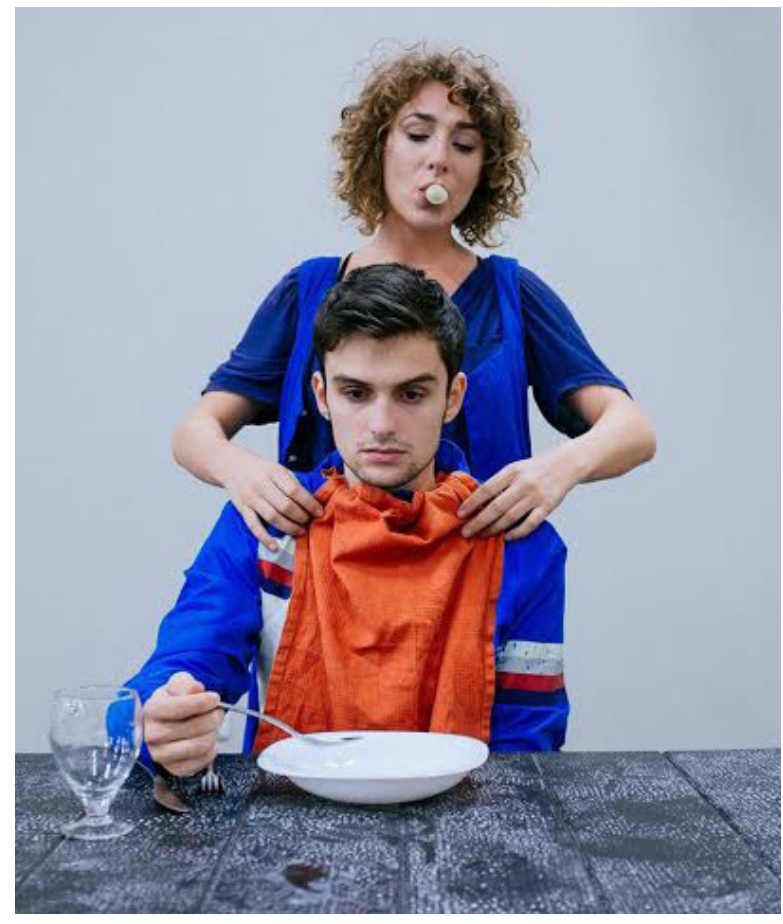

Fuente: Dragos Malaescu morales" versus "personajes inmorales", "amigos" versus "enemigos", etc.

Es verdad que el espectador sabe muy poco sobre Omy (Lucian Teodor Rus), pero lo mismo se puede decir de los otros dos personajes que aparecen sobre el escenario ${ }^{4}$. Kora, tal y como está interpretada por Silva Helena Schmidt, es una mujer de edad media que antes practicaba el ballet y que vino a América para ahorrar dinero y estudiar medicina (Stanescu, p. 11), pero terminó casándose con Chris (Andrei Stehan).

El marido de Kora tiene 39 años y su ocupación permanece como un "misterio", ya que al espectador no se le da ninguna clave sobre su pasado y sus auténticas aspiraciones. En la obra es especificado que los dos hablan "inglés con acento" $y$, en un determinado momento en el texto, al recordar los años cuando trabajaba como prostituta, Kora dice que "a todas las chicas de Europa del Este se les llamaba Natasha" (Stanescu, p. 28). Sin embargo, el director elige darle a Kora una identidad griega en la puesta en escena.

Pese a la falta de especificaciones sobre la nacionalidad de Chris, sí sabemos que él también es un inmigrante que vino a los EEUU con el afán de construir un futuro más próspero. Además, los pocos detalles que se facilitan a los espectadores sobre el pasado de Omy son brindados por Chris, cuando este se lo presenta a Kora: "no tiene padres. Huérfano. Criador de

${ }^{4}$ Jerry, el comerciante de órganos que está al frente del negocio es constantemente mencionado por la pareja, pero nunca aparece sobre el escenario. 
cerdos", "No habla. Sólo mira la pared... Está mal en la cabeza" (Stanescu, p. 3), mientras Kora apunta que el chico viene desde "un país del tercer mundo".

Todos los personajes están gobernados por el afán de hacer dinero para poder sobrevivir -sus conversaciones, interacciones, tratos y contactos físicos giran alrededor de ese tema-, una situación que, en términos foucaultianos, se traduciría como la unión destructiva entre "el poder asesino y el poder soberano" (2003, p. 259). Al mismo tiempo, todos provienen o bien de países pobres, o de entornos marcados por la pobreza, situaciones que no les ofrecieron la posibilidad de cumplir sus sueños en sus tierras natales; todos pertenecen a comunidades desparramadas, invisibles, obligados por la pobreza y la inseguridad en sus países a buscar refugios en los Estados Unidos. Pero ¿es este vínculo suficiente para aniquilar todas las fronteras socialmente impuestas entre estos seres deshumanizados que buscan albergue y salvación?

"Que descanses en tierra americana. Yo no les dejaría que te tiren en el basurero. ¡Qué coño! Tú te merecías un entierro apropiado; no eres un cerdo, eres una persona [énfasis agregado]" (Stanescu, p. 23). Así es como le habla Chris a Omy durante el quinto sueño de la obra. En la producción de Bucarest de Andrei Majeri', la representación de la pesadilla de Chris, concebida por la directora Ioana Paun, es sumamente representativa de las relaciones de poder establecidas entre ellos. El discurso de Chris, expresado por una voz en off, se encuentra en claro contraste con la manera en que se representan las figuras escénicas: aunque su discurso provoca al espectador imaginarse a un Chris bastante cínico enterrando a Omy, lo que en efecto se ve en el escenario es una inversión de las relaciones de poder. Por tanto, Chris es traído al escenario sobre un soporte que parece a la vez a un ataúd y a una camilla, con el cuerpo entero cubierto de semillas de girasol. Mientras recuerda su corto y banal encuentro con su "víctima" Omy, Chris, inmóvil e indefenso, es observado por Omy, su mirada tan neutra como siempre, vestido todo de negro, pero con un sentido de redefinida dignidad visible en su expresión corporal. Sólo al final de la obra se le permite al espectador ver la relación entre Chris y Omy, pero en ese punto, Chris parece esforzarse en convencerse de que tendría que considerar al adolescente como nada más que un mero cuerpo "inútil", cuyos riñones le podrían traer una ganancia: "Vamos a sacar 10.000 por él ¡Una fortuna!” (Stanescu, p. 3). Constantemente atrapado entre la aparente voluntad a sangre fría de hacer dinero - una actitud que, de hecho, nunca logra adoptar por completo- y su amor hacia su esposa, Chris elige actuar como "colonizador" en su relación con Omy. Aunque nunca se muestra explícitamente agresivo, Chris parece gozar de cada

\footnotetext{
${ }^{5} \mathrm{He}$ de mencionar que el director Andrei Majeri invitó a cinco otros artistas rumanos de diferentes medios a tomar parte en su producción de Orgánico y crear sus mise-en-scènes individuales para las secuencias de sueño del texto. Se trata de Ada Milea (música), Arcadie Rusu (coreógrafo), Tudor Giurgiu (director de cine), Ioana Paun (directora de teatro) y Les Ateliers Nomad (artistas visuales new media).
} 
ocasión en que pueda desplegar su autoridad ofensiva en frente del desamparado y vulnerable exgranjero. Ya sea a través de sus gestos, su discurso o su participación en negocios ilícitos, Chris basa sus interacciones con el vulnerable Otro en estrategias de distorsión. Al hacer esto, no solo distorsiona la identidad y el valor humano de Omy, sino también los mismos conceptos de moralidad e inmoralidad: "Nosotros damos a todos lo que necesitan; Omy necesita plata para vivir, el otro tipo necesita un riñón. Es un trato justo. Somos pequeños dioses, salvadores... OK, benefactores, si así lo quieres" (Stanescu, p. 8), le dice él a su incrédula mujer.

Por otro lado, la incapacidad de Kora para "relativizar" el valor de un ser humano tal y como lo hace su marido la coloca en una posición moral superior, aunque ni la sociedad en la que vivía - ni tampoco la sociedad en que actualmente vive- le dieron la oportunidad de poner en práctica sus verdaderos estándares éticos. A lo largo de la mayoría de sus apariciones en el performance teatral, Kora parece abarcar una serie de clichés frecuentemente asociados con la representación contemporánea de "las chicas de Europa del Este". Siempre frenética, a veces hasta el borde de la histeria, pero sin embargo "sensual" y "exótica"; Kora es, al mismo tiempo, una intachable amante, esposa, ama de casa y cocinera; es decir, parece personificar el "ideal femenino" supuestamente cultivado en los países de Europa del Sur-Este.

Saviana Stanescu, ella misma nacida en Rumania y actualmente ciudadana de los Estados Unidos, sintetiza perfectamente este constructo patriarcal cuando Chris le dice a Kora que "Eso es lo que significa ser esposa, mi amor: puta entre las sabanas, chef en la cocina y dama en la calle" (Stanescu, p. 10). Como América no le brindó todas las oportunidades que ella esperaba, Kora, según la perspectiva de Majeri, pasa el día ilusionándose en que por fin podrá llegar a ser enfermera y cambiando sus pelucas coloridas y quizás un poco cursis, para expresar su falta de estabilidad y su deseo infatigable de cambiar el actual estado de las cosas.

Poco antes de su intento de escaparse con Omy para rescatarlo de Jerry y Chris, Kora, mostrando una apariencia agotada -y cuya "sensualidad" estaba visiblemente mermada-, le cuenta al joven la historia de cómo su sueño americano se había convertido en pesadilla: "Yo era la más hermosa... Se suponía que iba a tener un gran futuro... Tuve que arriesgarme y venir para la puta América... iporque AHÍ te puedes convertir en una estrella, ahí todo es posible, ahí se encuentra el puto paraíso! Me apodaron «Natasha-Boca-Aterciopelada» por ese entonces... (ríe) Y eso no sólo porque sabía hablar con dulzura..." (Stanescu, p. 28).

Aunque tanto el texto como la producción escénica aluden ocasionalmente a una visión erotizada de Kora en relación con Omy, sobre todo en una de las escenas de sueño, la fuerza dominante en sus interacciones es la actitud maternal hacía el perturbado joven desconocido. Después de fallar en convertirse en bailarina, doctora y madre, Kora convierte a Omy en la 
proyección de sus sueños y esperanzas potenciales como madre: "Hubiéramos podido tener un hijo como él", le dice con enfado a Chris.

Por consecuencia, debido a una mezcla de compasión natural, sentido de una existencia incumplida y aspiraciones maternas, Kora actúa de una manera que demuestra su voluntad de transmitirle a Omy un sentido de reemplazo después de su desplazamiento traumático. Logra este objetivo no tanto a través de "estrategias" - dado que la faltan tanto el pragmatismo como la voluntad para actuar conforme a dichos esquemas-como de su compromiso a una relación basada en valores humanos fundamentales. La protección y el cuidado que manifiesta hacia Omy funcionan como remedio para el rechazo social que los dos sufren desde su posición de elementos marginales. Por poco tiempo, Kora se opone infatigablemente a la estrategia de distorsión de Chris a través de propia estrategia de adopción.

Los tres personajes desplazados de Orgánico van negociando su trayectoria desde la periferia hacia el centro en maneras diferentes y antitéticas; aunque queda claro que todos pertenecen a la periferia desde el punto de vista de su relevancia y aceptación social, el grado en que aceptan su propio estatus es el que varía y los diferencia. Aunque su temperamento dinámico -y Kora está siempre representada como tal por la actriz Silva Helena Schmidt en el espectáculo de Majeri- pueda hacer creer al espectador que se encuentran siempre a punto de hacer algo y aún que se están preparando para su "gran futuro", el texto aclara que la perspectiva de un cambio es prácticamente nula. Dolorosamente consciente de la manera en que sería percibida si tuviera una vida social más activa -a lo que, no obstante, la pareja decidió renunciar hace años, ostensiblemente debido a sus negocios ilícitos (Stanescu, p. 10)- Kora nunca acusa a "la sociedad" en términos envenenados.

Pese a los maltratos físicos que el espectador puede inferir que haya experimentado mientras trabajaba como prostituta, Kora describe una serie de escenas violentas haciendo uso del humor y la ironía: "Yo era la reina del baile erótico. Me invitaban a los hoteles más elegantes... Gerentes, banqueros, políticos... Gente con educación... es gracioso ver qué estúpidos parecían desnudos, los pelos ridículos de sus espaldas, la lengua meneando como perros." (Stanescu, 27). La estrategia de reemplazo de Kora consiste en una síntesis entre la acción del presente -es decir, su intento de rescatar a Omy y, por tanto, salvar también su ser deshumanizado- y la proyección del futuro: en el futuro, los tres tendrán más dinero, en el futuro ella se convertirá en enfermera gozando de una vida estable, en el futuro ella y Chris irán de vacaciones a lugares soleados y costosos.

En cambio, Chris se coloca a sí mismo en la posición patriarcal del "salvador": es su deber, como hombre y esposo, hacer dinero y consecuentemente reconstruir su posición social; incluso, si a veces esto supone la explotación consciente de otras personas. Supuestamente por 
orgullo, nunca habla sobre sí mismo como migrante o miembro de una comunidad dispersa, aunque esta es, evidentemente, la condición más decisiva e influyente de su existencia, la misma condición que lo llevó a sus presentes tribulaciones y ahora lo sigue llevando hacia un futuro sin esperanza. Su relación con el centro está fundada tanto en fascinación como en frustración: él está preparado para hacer lo que sea con tal de ganarse la aceptación, pero, de forma realista, se da cuenta que llegar a ese punto es muy poco probable. Esto lo empuja a la amargura y a una contradicción más y más visible entre sus inclinaciones profundamente humanas y la estrategia de distorsión que discutimos antes. Mientras más se rehúsa a reconocerse como una figura marginal, más lo es.

Desde una perspectiva dramatúrgica, Omy representa la presencia más problemática del escenario, ya que su personaje sólo se construye a través de expresiones corporales. En las raras ocasiones en que utiliza el lenguaje, su habla está siempre desarticulada, fragmentada y es disfuncional con respecto a la interacción dialógica. Consecuentemente, su discapacidad, junto a su condición de migrante temporalmente abusado y usado para el tráfico de órganos, no solamente lo desplaza del centro societal sino que lo empuja a la absoluta intrascendencia. Excluidos y marginalizados, Chris y Kora no cuentan con nadie más para rehacer sus vidas y mejorar su presente condición, y eso es precisamente lo que parecen resueltos a hacer al final de la obra, cuando están considerando su mudanza a Florida.

Por otro lado, Omy no puede sobrevivir sin ayuda del exterior. Pobre, huérfano, epiléptico, despojado hasta de los muy pocos recursos en los cuales se amparaba cuando tuvo que dejar su granja de cerdos porque "las autoridades locales los mataron a todos [los cerdos] por eso de la gripe porcina” (Stanescu, p. 7), Omy nunca tiene la posibilidad de quejarse y expresar su descontento. Él es invisible para la comunidad de los marginales, ya que no puede afirmarse a causa de sus discapacidades, como para los privilegiados, para quienes simplemente no existe. Si muriese, su muerte no tendría consecuencia alguna. Si vive, solamente puede continuar en el mismo trayecto de la invisibilidad e irrelevancia. El reemplazo de su adolescencia perdida parece ser un proyecto inalcanzable.

Es solo en el último sueño de la obra -el que traje a discusión a principios de este apartado- que Omy utiliza un lenguaje coherente, articulado para expresarse. Rodeado por la bandera estadounidense, símbolo, a la vez, de la suprema esperanza y el supremo fracaso, por fin es capaz de dar voz a su entendimiento de la realidad, del cual el espectador no había tenido ninguna indicación hasta este punto del espectáculo: "Estoy corriendo, chirriando como un cerdo. Me quieren apuñalar. ¿Pero sabes qué, mami? Yo voy a parar de correr” (Stanescu, p. 30).

Según lo que entendimos de la performance, su reemplazo es alcanzable solamente tras la muerte, sinónima, en este caso, con la extracción de un mundo que le había negado 
tanto el derecho a tener una voz como la capacidad de afirmar su presencia como cuerpo. En términos foucaultianos, Omy es la figura más radicalmente representativa de las consecuencias del despliegue abusivo del biopoder: "Ahora la muerte se convierte, por contraste, en el momento cuando el individuo se escapa de todo poder, se revierte a sí mismo y se retrae, por así decirlo, en su propia privacidad. El poder ya no reconoce más a la muerte. El poder literalmente ignora la muerte" [énfasis agregado] (Foucault, 2003, p. 248).

En el Orgánico de Andrei Majeri, los espectadores presencian el gradual borramiento de tres personajes marginalizados. Si de algún modo logran sobrevivir o, por lo menos, experimentar un vínculo humano autentico antes de morir, se debe a su poder de aniquilar sus propias fronteras interiores, ya que las fronteras impuestas por la biopolítica son siempre imposibles de transgredir en la ausencia de una fuerza colectiva.

Desde 2015, ciudadanos provenientes de todo el mundo han empezado a asistir al gradual borrado de miles de migrantes huyendo de los desastres que han tragado sus comunidades por culpa de las guerras y los conflictos. Si la aniquilación de las fronteras culturales y políticas es posible -ya que las fronteras físicas han sido fuertemente desafiadas por los migrantes, a veces, demasiadas veces, a costa de sus propias vidas- está por verse.

Pese al inquietante número de vidas humanas perdidas o amenazadas, el rol activo asumido por el teatro y los artistas de perfomance a nivel internacional no puede más que infundir esperanza para el futuro. Un futuro en que la potencial contribución de aquellos que provienen de comunidades dispersas pueda cambiar de manera radical el rostro de las artes performativas tal y como los entendemos hoy dentro del marco occidental.

\section{Referencias}

Deleuze, G. \& Guattari, F. (2005). A Thousand Plateaus. Capitalism and Schizophrenia. Minneapolis: University of Minnesota Press.

Deleuze, G. \& Guattari F. (2002). Capítulo 1227 - Tratado de nomadología: la máquina de guerra. En Mil Mesetas. Capitalismo y esquizofrenia. Valencia: Pre-Textos.

Fairuz , F. (s.f.). Sitio oficial. Recuperado de http://www.faridfairuz.ro//

Foucault, M. (2003). Society Must Be Defended. Lectures at the Collège de France, 1975-76. New York: Picador.

Foucault, M. (2008). The Birth of Biopolitics. Lectures at the Collège de France, 1978-79. New York: Palgrave Macmillan. 
Haydon, A. (21 de septiembre de 2013). Realia - Centrul National al Dansului [Bucharest Dance Meetings [web log post]. Recuperado de http://postcardsgods.blogspot.ro/2013/09/realia-centrul-national-al-dansului.html

Stanescu, S. (s.f.). Useless. Manuscrito inédito.

Stephenson, J. (2013). Performing Autobiography: Contemporary Canadian Drama. Toronto: University of Toronto Press.

Useless by Saviana Stanescu, Directed by José Zayas. (s.f.). Recuperado de http://irttheater. org/3b-development-series/useless/

Visniec, M. (2015). Mihai Mihalcea, coregraf roman in cautare de oxigenidentitar. RFI Romania. Recuperado de http://www.rfi.ro/special-paris-78714-mihai-mihalcea-coregraf-roman-cautare-de-oxigen-identitar 